\title{
ENTRE LA TRADICIÓN Y LA INTEGRACIÓN: RÉQUIEM PARA UN VIERNES A LA NOCHE DE GERMÁN ROZENMACHER Y SU ESTRENO EN EL TEATRO IFT
}

\author{
BETWEEN TRADITION AND INTEGRATION: RÉQUIEM PARA \\ UN VIERNES A LA NOCHE BY GERMÁN ROZENMACHER \\ AND ITS PREMIERE AT THE IFT TEATER
}

\author{
Paula Ansaldo \\ UBA/IAE-CONICET. Argentina \\ paulansaldo@hotmail.com
}

\begin{abstract}
Resumen: En este trabajo abordaremos el estreno de la obra Réquiem para un viernes a la noche de Germán Rozenmacher en el teatro IFT (Idisher Folks Teater, Teatro Popular Judío) en 1964. Sostenemos que se trata no sólo de una obra emblemática de la dramaturgia judeo-argentina, sino de un estreno que da cuenta de un cambio de orientación en el IFT, en tanto expresa un giro en las preocupaciones de sus integrantes que buscaban tener una mayor llegada a los espectadores de la nueva generación, así como al público no judío. Este objetivo los había llevado ya a partir de 1957 a comenzar a realizar sus obras en castellano, cuando hasta entonces se realizaban únicamente en ídish. Esto respondía a la voluntad del IFT de lograr una mayor integración tanto en la sociedad argentina como en el movimiento de teatro independiente. Y en este sentido, consideramos el estreno de la primera obra de Rozenmacher -un autor joven que le daba voz a las preocupaciones de la nueva generación al retratar el conflicto generacional y el choque entre dos maneras contrapuestas de ser judío y argentino- como un momento cúlmine de este proceso, en el cual indagaremos.
\end{abstract}

Palabras clave: Germán Rozenmacher; Dramaturgia judeoargentina; Réquiem para un viernes a la noche; Teatro IFT.

\begin{abstract}
In this essay, we will discuss the premiere of Germán Rozenmacher's Réquiem para un viernes a la noche at the IFT theatre (Idisher Folks Teater, Jewish Popular Theater) in 1964. We argue that it is not only an emblematic work of Jewish Argentinian Dramaturgy, but a premiere that reveals a change of orientation in the IFT, as it expresses a turn in the concerns of its members who sought to have a greater arrival to the spectators of the new generation, as well as to the non-Jewish public. This objective had already led them from 1957 to begin to realize their works in Castilian, when until then they were realized only in Yiddish. This was in response to the IFT's desire to achieve greater integration in both Argentine society and the
\end{abstract}


independent theater movement. And in this sense, we consider the premiere of the first work of Rozenmacher - a young author who gave voice to the concerns of the new generation in portraying the generational conflict and the clash between two opposing ways of being Jewish and Argentine - as a moment culminate of this process, in which we inquire.

Keywords: Germán Rozenmacher, Jewish Argentinian Dramaturgy, Réquiem para un viernes a la noche, IFT Theatre.

Recibido: 28.09.2017. Aceptado: 24.05.2018

O ermán Rozenmacher nació en Buenos Aires en 1936 en una familia de $\checkmark$ judíos inmigrantes provenientes de Rusia. Comenzó trabajando como periodista en diversos diarios y revistas y en 1962 publicó su primer libro de cuentos Cabecita negra, por el cual recibió numerosos premios. En 1964 estrenó en el teatro IFT la obra Réquiem para un viernes a la noche que resultó un completo éxito de público y crítica, otorgándole un gran reconocimiento como dramaturgo dentro del campo teatral de la época. En 1970 finalizó su segunda obra teatral, Simón Brumelstein, el caballero de indias, donde profundizaba en los conflictos planteados en su primer trabajo. La obra fue estrenada póstumamente en 1982, luego de su trágica muerte en 1971 a la edad de 35 años ${ }^{1}$.

En este trabajo nos centraremos en Réquiem para un viernes a la noche ya que consideramos que se trata no sólo de un texto emblemático de la dramaturgia judeo-argentina, sino de un estreno que da cuenta de un cambio de orientación en el teatro IFT, en tanto expresa un giro en las preocupaciones de sus integrantes que comenzaban a buscar una mayor llegada a los espectadores de la nueva generación, así como al público no judío.

El IFT (Idisher Folks Teater - Teatro Popular Judío) había surgido en 1932 con el nombre de IDRAMST (Idishe Dramatishe Stude - Estudio Dramático Judío) y se constituyó como el primer teatro independiente judío de Buenos Aires que al igual que otros grupos independientes del período, tales como el Teatro del Pueblo de Leónidas Barletta, se posicionó

${ }^{1}$ Debido a esto y en homenaje a su memoria, el Centro Cultural Rojas (UBA) instituyó en 1999 el premio Germán Rozenmacher de Nueva Dramaturgia destinado a dramaturgos jóvenes de hasta 35 años. 
como una "nueva modalidad de hacer y conceptualizar el teatro, que implicó cambios en materia de poéticas, formas de producción y organización grupal, vínculos con el público, militancia artística y política y teorías estéticas" (Dubatti, 2012: 81).

Este grupo se diferenciaba del resto de los teatros ídish de Buenos Aires por su compromiso político y su concepción del arte como una herramienta de transformación social, así como por su forma de financiación económica que buscaba independizarse del capital empresarial y su búsqueda de lucro, sustentándose por medio de los aportes de sus asociados. Sus integrantes rechazaban el teatro mercantilizado, al que creían responsable de empobrecer y adormecer las mentes de los espectadores. Concebían en cambio al teatro como un movilizador de conciencias y al igual que el Teatro del Pueblo, seguían las ideas de Romain Rolland quien abogaba por un teatro que satisficiera las necesidades de un público estrictamente popular. En este sentido, los guiaba la frase de I.L. Peretz - grabada luego en una de las paredes del IFT - que sostenía que el teatro era a shul far dervaksene, una "escuela para adultos". Por otro lado, el grupo se posicionaba como un teatro de arte, sentando sus bases en la búsqueda de una modernización estética en cuanto al lenguaje teatral, con el fin de elevar el nivel cultural del teatro judío en Buenos Aires, enriqueciéndolo con las nuevas tendencias provenientes de Europa (tales como el sistema de Stanislavsky, el pensamiento escénico de Max Reinhardt, la poética expresionista, entre otras). El IFT buscaba, así, instruir a los espectadores tanto en materia política como estética.

Pero para la década del 6o', este teatro ya había dejado atrás su época de mayor auge, y muchos cambios se habían operado al interior de la institución. En primer lugar, el elenco había comenzado a partir de 1957 -con el estreno de El diario de Ana Frank dirigida por Oscar Fessler- a montar sus obras completamente en castellano, cuando hasta entonces realizaba sus representaciones únicamente en ídish. Esto respondía a la voluntad del IFT de lograr una mayor integración tanto en la sociedad argentina como en el movimiento de teatro independiente.

Para ese momento, el teatro formaba ya parte de la FATI (Federación Argentina de Teatros Independientes, creada en 1946), cuyo propósito era nuclear a los diferentes grupos teatrales e impulsar así una mayor unidad al interior del movimiento de teatro independiente. El paso al castellano era 
en este sentido clave, ya que les permitía superar la barrera idiomática que lo separaba del resto de los grupos independientes, y de esta forma ampliar su accionar al poder llegar a un público más amplio, contribuyendo así en mayor medida al objetivo pedagógico común a los teatros agrupados en la FATI.

Existían también razones políticas en tanto que el IFT pertenecía al ICUF (Idisher Cultur Farband, Federación Cultural Judía)² que, según sostienen tanto Israel Lotersztain (2014), como Ariel Svarch (2005) y Nerina Visacovsky (2016), comenzó ese mismo año una campaña para relegar el ídish en beneficio del castellano en todas las instituciones que lo integraban, siguiendo los lineamientos del comunismo Soviético y la política del Partido Comunista Argentino que veía el idishismo como una forma de sectarismo cultural e idiomático que impedía "acriollar" el partido (Visacovsky, 2016: 115). La ideología que sostenía la dirigencia del ICUF estaba en consonancia con esta decisión, en tanto el objetivo de la institución era "partir de 'lo particular' (el judaísmo) hacia 'lo universal' (toda la sociedad)" (Visacovsky, 2016: 146). En este sentido, el apego a la lengua se interponía en el camino de integración con el resto de la sociedad e incitaba a sus miembros a cerrarse en un mundo únicamente de judíos. Los icufistas consideraban que los problemas de la humanidad eran universales y se oponían a las posturas particularistas que sostenían por ejemplo los sectores sionistas, preocupados exclusivamente por la problemática judía. $\mathrm{Y}$ en tanto que "el legado judeo-progresista era universal" (Visacovsky, 2016: 178), había de ser transmitido en el idioma en el que la mayoría de la sociedad pudiese comprenderlo. Por esta razón, los intelectuales del IFT sostenían que el teatro no podía:

(...) ser ajeno a los cambios operados en la idiosincrasia de la colectividad, a las nuevas modalidades adquiridas por ella tras tantas décadas de acrisolamiento en suelo argentino, ni permanecer aislado del vasto

\footnotetext{
${ }^{2}$ Fundado en 1941 de acuerdo a las conclusiones del Congreso de Cultura Judía Laica, llevado a cabo en París en 1937. El ICUF central reunió diversas instituciones entre las cuales se encontraban escuelas (como por ejemplo I. L. Peretz, Jaim Zhitlovsky, Janus Korchak y Domingo Faustino Sarmiento), clubes (Asociación Cultural y Deportiva Scholem Aleijem, Zumerland, Club Israelita de Avellaneda) y centros culturales (Centro Cultural David Berguelson, Centro Cultural Israelita Dr. E. Ringelblum, Centro Cultural Peretz Hirschbein).
} 
panorama de la cultura nacional. De tal modo, sin dejar de cultivar y expandir las más elevadas y universales manifestaciones de la cultura judía en ídish, su entroncamiento en la vida argentina, las necesidades crecientes de las nuevas generaciones que ya no hablan la lengua materna, han hecho impostergable el uso, también, del idioma común a todos los habitantes del suelo patrio, en el escenario del IFT (Weltman, 1957: 4).

Como puede verse, la preocupación por atraer a la juventud era primordial para los integrantes de un teatro que había buscado desde un comienzo posicionarse - no como un mero medio de esparcimiento- sino como un instrumento para la elevación cultural de la comunidad. En consonancia con este objetivo pedagógico, la necesidad de extender su influencia moral a las nuevas generaciones de judíos hacía aparecer como necesario el abandono de un idioma que se convertía en un factor de desconexión para los jóvenes, que ya no lo hablaban ni lo comprendían.

Con el paso al castellano entonces, los integrantes del IFT se mantenían fieles a su misión fundante que era educar al pueblo. El ídish dejaba así de verse como un instrumento útil, pasando a ser incluso un obstáculo para el logro de sus objetivos que era la construcción de un mundo mejor por medio de la cultura, mientras que el castellano resultaba una herramienta más apropiada y eficaz para alcanzarlos, por lo que su adopción en desmedro del ídish aparecía a los ojos de sus integrantes como un paso lógico. A partir de El diario de Ana Frank entonces, el IFT postulaba que era posible conservar su identidad cultural e institucional judía, aun en un idioma diferente al de sus orígenes, en tanto que el contenido judío dejaba de verse como indisolublemente unido a la lengua.

Es en este contexto que se produce el estreno de la primera obra de Rozenmacher el 21 de mayo de 1964, dirigida por Yirair Mossian y protagonizada por José María Gutiérrez (Sholem) como actor invitado, e Ignacio Finder (Max), Héctor Saleme (David) y Marta Gam (Leie), que eran de los más importantes actores del elenco en ese momento. El espectáculo permaneció tres temporadas en cartel y continuó siendo un completo éxito de público durante todas sus funciones.

Consideramos a este estreno como una forma de culminación del proceso iniciado en 1957 , en la medida en que se trata de una obra escrita por un dramaturgo judeo-argentino pero no en ídish, sino en español. Si 
bien sabemos que el IFT había estrenado ya obras de autores argentinos con anterioridad -como es el caso de Cuando aquí había reyes de González Pacheco en 1947, traducido al ídish para dar a conocer la dramaturgia argentina a los espectadores judíos que no asistían al teatro en español-, se trataba de la primera vez que se representaba en castellano una obra de temática específicamente judía, con personajes judíos y escrita por un autor judío. Rozenmacher era a su vez un autor joven que le daba voz a las preocupaciones de la nueva generación, a las que por ese entonces el IFT buscaba con tanto esfuerzo alcanzar.

\section{La obra}

Réquiem para un viernes a la noche se centra en el conflicto de David y su padre, Sholem Abramson, que oficia de cantor en la sinagoga y desea que su hijo siga sus pasos honrando la tradición familiar. Pero a pesar de poseer una bella voz, David pretende en cambio ser escritor y por si esto fuera poco, se ha enamorado de María, una muchacha no-judía, y quiere casarse con ella.

El argumento es en cierta medida autobiográfico: sólo unos días antes del estreno, Rozenmacher se había casado con Amelia "Chana” Figueiredo, a quien está dedicada la obra y al igual que el de su personaje, su padre oficiaba de cantor en la sinagoga. En este sentido, partir de su propia situación era para él un modo de creación, ya que sostenía que "la autobiografía es la única manera de comenzar a abrir nuestra realidad, de ir probando hasta ver a dónde se llega" (Rozenmacher, 2013: 883).

Por medio de su propia historia entonces, el autor hacía eco de una realidad y una problemática de su generación, al abordar la problemática del choque generacional y presentar dos maneras contrapuestas de ser judío y argentino, instalando así la pregunta sobre cómo conciliar el antes y el ahora, el aquí y el allá, lo propio y lo ajeno.

Estas tensiones entre el pasado y el presente aparecían en la pieza a partir de diferentes recursos. En primer lugar, la obra comienza con la figura del tío Max, el hermano de Sholem, que si bien también es cantante, no oficia en la sinagoga sino en el teatro. Se trata de un personaje que vive de sus glorias pasadas cuando era un afamado actor de la escena ídish, "el rey de 
la opereta judía”. El ambiente que rodea a este personaje se describe en las didascalias como un espacio de nostalgia y anhelo por un pasado que ya no existe: suena "música de vieja opereta judía", "baila al viejo estilo", "todo él es un esfuerzo sobrehumano de no envejecer" (Rozenmacher, 2013: 271) y su primer parlamento interpela a los espectadores preguntándoles si alguien lo reconoce, si hay algún viejo en la sala. Todo nos indica que se trata de un personaje que no pertenece al presente de la representación, sino que proviene de otro tiempo, del tiempo de lo que ya es viejo. No es casual entonces que sea él, el encargado de presentar la historia de la familia Abramson, brindándole un marco e imponiendo así el tono de lo que se desplegará a continuación. De esta forma, por medio de un procedimiento metateatral, Max representa una escena frente a un público que es a la vez real y ficcional, y toda la obra aparece como su relato.

Como puede verse $-\mathrm{y}$ a pesar de que tradicionalmente se incluye la obra de Rozenmacher como parte del realismo crítico característico de los dramaturgos de la Generación del ' $60^{3}-$ la obertura de la pieza utiliza un mecanismo frontal que rompe con la ilusión realista, al colocar un personaje que se dirige a los espectadores rompiendo la cuarta pared, y estableciendo un juego con el límite entre la realidad y la ficción. Consideramos que este procedimiento cumple la función de crear una suerte de complicidad con el espectador, invitándolo a sentirse parte del mundo reflejado por la obra, y de proyectar al interior del mundo ficcional su propia realidad. Esto se debe a que en la concepción teatral de Rozenmacher "ir al teatro es verse (...) el teatro es una ceremonia, porque todos juntos estamos oficiando un ritual. Ritual cuyo objetivo es descubrirnos a nosotros mismos: ese es el sentido del teatro" (en Herzovich, 1971: 15). Por medio del personaje de Max entonces, el autor invitaba al público a animarse a verse a sí mismo, a reconocerse. Este objetivo coincidía con la función que los integrantes del IFT le otorgaban al teatro, ya que como hemos visto, no lo concebían como un mero entretenimiento que le permitía al espectador evadir sus preocupaciones, sino como un modo de enfrentarse con ellas, movilizando y desafiando sus concepciones en pos de un cambio. Así lo señalaba el pro-

\footnotetext{
${ }^{3}$ Entre los que se encuentran, entre otros, Roberto "Tito" Cossa, Ricardo Halac, Carlos Somigliana y Ricardo Monti.
} 
grama de mano que invitaba al reestreno de la obra con la frase: "vuelve a la escena que la consagró en la temporada 1964 para hacer impacto en su conciencia".

El espacio en el que se desarrolla la acción es el comedor de la casa de los Abramson, descripto en las didascalias como la misma atmósfera decadente y melancólica del comienzo: "El clima de todo es abrumador, sofocante, hermético, infinitamente triste y pobre" (Rozenmacher, 2013: 9). Al igual que sus habitantes, la casa se ha quedado estancada en un tiempo que ya se fue. Por medio de una suerte de procedimiento expresionista, el departamento enuncia el sentir de la familia que se refugia en un pasado de mayor alegría, frente a un presente que aparece como desolador. El recuerdo de la gran familia Abramson de Capule -el pueblo de Rusia en el que vivieron antes de venir a la Argentina- compensa la incertidumbre del presente en el cual Sholem ya no es el prestigioso cantor de antaño y donde todos los días teme por la pérdida de su fuente de trabajo y orgullo. Frente a esto, ha depositado todas las esperanzas en su único hijo, David, quien constantemente frustra sus expectativas al no comportarse como se espera de él.

La obra transcurre en su totalidad el día viernes, en la cena de la noche de Shabat, a la cual David no ha llegado. Su presencia ausente en el ritual del viernes tiñe toda la primera escena, en tanto se convierte en una metáfora de su rechazo a cumplir con el mandato familiar y ser, de esa forma, un continuador de la tradición judía. El clima trágico está planteado así desde el comienzo, en tanto David no llega, y a los ojos de su padre esto lo convierte en un traidor y un renegado.

Su deseo de casarse con una no judía es, en este sentido, simplemente la última de sus decisiones que atenta contra el mandato familiar, pero esta vez de manera tan profunda y radical que no podrá más que llevar a la ruptura definitiva. De esta forma, como señala Senkman, "la pareja formada por David y María sólo es el detonante del verdadero conflicto de esta obra teatral: aquel que enfrenta dos maneras diferentes de concebir y asumir la identidad judía" (1983: 304). Para Sholem ser judío es respetar las leyes, cumplir con la tradición y continuar la larga cadena de generaciones, honrando la memoria de aquellos que fueron perseguidos:

SHOLEM: iPero hay cosas que no se deben hacer, David! iNo se pueden hacer, yo nunca las hice yo nunca escuché que las hicieran! Nos persi- 
guen, así es, siempre fue así. ¿Y qué otro orgullo nos queda que seguir siendo 'lo que somos? (Rozenmacher, 2013: 302).

Para el padre la herencia es irrenunciable y define una manera de entender 'lo que somos' que pasa de generación en generación como algo dado. Para David, en cambio, la identidad es fruto de redefiniciones y transformaciones, donde el ser judío es un elemento más que se transforma y se enriquece en el contacto con otros. Casarse con una no judía es, entonces, una manera más de ser parte del país en el que nació y que siente suyo, pero sin dejar por ello de reconocerse como judío. A Sholem, en cambio, su judaísmo lo define de manera absoluta y divide al mundo entre un nosotros y un ellos. Para él ser judío es seguir los principios que marca la tradición y no hacerlo no es una alternativa posible, por lo que convierte automáticamente a quien lo hace en un goy, en un Otro que forma parte de un "ellos" que se opone a un "nosotros":

SHOLEM: iEs un antisemita! Es más que eso. Para mí es un traidor. Es un hijo que traicionó a su padre (...) Tenemos un goy. iPeor que un goy! iUn enemigo en la casa! (Rozenmacher, 2013: 286).

La culpa del hijo es entonces no querer ser como su padre, ser diferente, y sobre todo pretender que su diferencia sea aceptada, ya que uno de los puntos fundamentales de la pieza es que David en todo momento espera la reconciliación con sus padres. Su intención no es cortar completamente el cordón umbilical que lo ata a la casa familiar, sino lograr el respeto por su individualidad y sus deseos. La obra es en este sentido trágica, ya que señala la incapacidad de las diferentes generaciones para entenderse y aceptarse el uno al otro. Ni el padre ni el hijo pueden cambiar su posición porque lo que está en juego es aquello que los define más profundamente en su identidad y los hace ser quienes son.

Así, al mostrar un personaje que se rebelaba contra el mandato paterno, la obra cuestionaba la imposición de una definición dada del ser judío y de cómo vivir acorde a ello. El protagonista de Rozenmacher, al igual que su autor, buscaba encontrar nuevas maneras para conciliar y redefinir la propia identidad, en tanto judío y argentino.

Esta búsqueda estaba a tono con las preocupaciones del IFT quien, a partir del paso al castellano, enfrentaba un proceso de redefinición de su 
identidad como institución. La obra funcionaba así como una suerte de legitimación de esta transformación identitaria que estaba atravesando el teatro, lo cual quedaba claramente evidenciado por el programa de mano que sostenía: "Rozenmacher siente en sí la vocación del ser nacional. El teatro IFT considera esta búsqueda, este aproximamiento una confirmación de su propia función". Cultivar una vocación nacional, hablar a todo el pueblo argentino y no únicamente al público judío se configuraba en esos años como una de las principales metas del IFT, por lo que sus integrantes destacaban la capacidad de Rozenmacher para "incorporarse en nuestra realidad argentina, para arraigarse en ella, para complejizarla con su particularidad", como señala el programa de mano.

De esta forma, se buscaba compartir y abrir la experiencia judía al mundo no judío, con el castellano como principal herramienta. Esta intención puede verse en la introducción de un glosario de palabras en ídish en el programa de mano, que traducía al español el significado de todas las palabras que se utilizaban en la obra, con el objetivo de no dejar afuera al público no judío. El mismo título de la obra utilizaba la palabra "réquiem" por sobre la palabra kadish para referirse a la oración de duelo, ya que apuntaba a un público que no necesariamente comprendía el concepto en hebreo, como se encarga de puntualizar el personaje de Max: "¿A que no saben qué quiere decir "kadish"? iQué van a saber! Es un réquiem, una oración para los difuntos" (Rozenmacher, 2013: 272). Lo mismo sucedía con el sintagma "viernes a la noche" que reemplazaba la palabra hebrea shabat, no tan conocida por fuera del mundo judío. Y por si eso no fuera suficiente, el programa de mano incluía una cita de Mendele Moijer Sfórim ${ }^{4}$ que explicaba la importancia del sábado para la cultura judía, de manera que todos pudieran comprenderla.

El objetivo de abrir el mundo judío al no-judío poniendo el eje en sus componentes universales, explica también la voluntad de Rozenmacher de desplegar procedimientos teatrales claros, tales como por ejemplo la elección de los nombres de los personajes que encarnan posiciones concretas: la muchacha no judía se llama María, y no aparece jamás en escena ni se dice nada respecto a ella más allá de aquello que genera el conflicto dra-

\footnotetext{
${ }^{4}$ Escritor judío, considerado el iniciador de la literatura ídish moderna.
} 
mático: su no pertenencia a la colectividad, claramente evidenciada por su nombre. El padre y el hijo, en cambio, tienen nombres que los identifican fácilmente como judíos, ya que se trata de nombres bíblicos que los ligan a una tradición determinada. Incluso su apellido, Abramson, significa "hijo de Abraham", el primer patriarca hebreo. De esta manera, los nombres que portan los marcan y los condicionan, obligándolos a hacerse cargo de un pasado compartido, con el cual cada uno de ellos se relaciona de maneras contrapuestas que terminan por enfrentarlos. Estos diferentes posicionamientos frente a lo judío, también son representados en la obra por medio de procedimientos muy concretos y explícitos, por ejemplo a partir de la relación que establecen los personajes con los objetos escénicos y por medio de la música. Como señala el personaje de Max en el prólogo, los Abramson son una familia de cantores y tanto él como Sholem entonan durante la obra diferentes canciones: melodías rituales en hebreo en el caso del padre y canciones folclóricas en ídish (Varshe Mains, $A$ ídishe mame) en el caso del tío, ligándose cada uno a su manera con el pasado y la tradición compartida. David en cambio, a pesar de que se señala que tiene una buena voz, no canta en ningún momento de la pieza, puesto que "ha olvidado las antiguas canciones, las religiosas y las tradicionales; y únicamente, como un muchacho porteño, silba” (Trastoy, Zayas de Lima, 2006: 160). Así, por medio de sus acciones escénicas, David hace explícita su transgresión al mandato familiar: se sienta en la silla de su padre cuando éste no está, subvirtiendo la norma del respeto a los padres, y se rehúsa a usar el talit y las filacterias que su padre quiere colocarle para el rito de shabat, arrojándolos lejos de sí con violencia, expresando así su rechazo por las creencias familiares.

Como hemos señalado, el conflicto generacional que escenifica la obra constituía una temática habitual de los dramaturgos jóvenes de la década del '6o, que abordaban en sus textos la crisis de la institución familiar, la dificultad de comunicación entre los padres y los hijos, y las formas contrapuestas de ver la vida de los jóvenes y los adultos. Durante este período, el teatro cumplió una función crítica del orden social al cuestionar "los límites de una sociabilidad destructiva e invitar implícitamente al advenimiento de un cambio" (Dubatti, 2012: 159).

En este sentido, poner en escena la obra de Rozenmacher no solamente estaba a tono con los objetivos del IFT sino que hacía eco también de 
la problemática propia que atravesaba el teatro. El conflicto generacional del que habla la obra, duplicaba y daba cuerpo a las tensiones que se estaban desarrollando al interior de la institución, donde se había producido un recambio generacional, en tanto una nueva camada de actores y directores jóvenes, tales como Manolo Iedvabni y Jaime Kogan, se habían incorporado de manera muy activa al elenco artístico y tenían cada vez más peso dentro del teatro. No es casual que una de las publicidades de la obra hiciera eco de esta cuestión usando como subtítulo la pregunta: “¿Qué ocurre entre dos generaciones con 30 años de diferencia?". Esta incomodidad y hastío con lo heredado que llevaban a una necesidad imperiosa de producir una trasformación, aparecían claramente en el discurso de David que funcionaba como una suerte de personaje delegado del autor y de su generación:

DAVID: No, papá, no me entendés... Pero ċes que no ves cómo me ahogo aquí dentro? ¿Qué se guarda en esta casa? ¿Qué querés de mí? Entro aquí y me siento en otro mundo. Entro aquí y me siento a mitad de camino de todo, no soy nada, no soy nadie. iEstoy cansado de hablar mitad en ídish y mitad en castellano! iEstoy cansado de vivir en el pasado, estoy cansado de ser un extranjero! (...) ¿Qué querés que te haga si soy distinto a vos? ¿'Te creés que no me duele? (Rozenmacher, 2013: 303).

La obra de Rozenmacher expresaba así las transformaciones que se habían producido y se estaban profundizando cada vez más en la comunidad judía de Buenos Aires, a la vez que fundaba una nueva dramaturgia judeoargentina que, en castellano y con un lenguaje teatral moderno, pudiera hacer dialogar los dos tiempos.

De esta forma, el cambio de orientación que se produjo en el IFT a raíz del paso al castellano, no implicó perder el componente judío, ni asimilarse completamente dejando de lado todo aquello que los singularizaba como comunidad dentro del Estado Nacional, sino que constituyó una manera de tender puentes que les permitieran hacer dialogar lo específicamente judío con lo universal, yendo de lo particular a lo general. Como sostenía el propio Rozenmacher, el desafío se convertía entonces "en lograr ese momento delicadísimo en el cual hablar de uno, es hablar de todos” (1964: 7). 


\section{Referencias}

Achun, S. (1982). "Repasando la historia”. Revista Teatro IFT. $50^{\circ}$ aniversario. Buenos Aires.

Ansaldo, P. (2015). "Rozenmacher, Goldenberg y Diament: la problemática del inmigrante en tres dramaturgos judeo-argentinos". Cuadernos Judaicos, $32,1-13$.

(2016). "El teatro como escuela para adultos: un recorrido por la historia del IFT en su tránsito del ídish al español”, en Skura, S.; Glocer, S. (comps.), Teatro ídish-argentino (1930-1950). Buenos Aires: Facultad de Filosofía y Letras, Colección Saberes.

Astro, A. (2006). "Más allá de la represión: la literatura ídish en América Latina”, en Huberman, A. y Meter, A. (eds.), Memoria y representación. Configuraciones culturales y literarias en el imaginario judío latinoamericano. Rosario: Beatriz Viterbo.

Dubatti, J. (2012). Cien años de teatro argentino: del Centenario a nuestros días, Buenos Aires: Biblos.

Foster, D. W. (1992). "Germán Rozenmacher: escribiendo la experiencia contemporánea judía en Argentina”. En: Pellettieri (comp.), Teatro y teatristas, Buenos Aires: Galerna.

Halac, R. (1971). "El teatro de German Rozenmacher y la tensión entre el judaísmo y la revolución”, Los Libros, $\mathrm{N}^{\circ}$ 23, Año III, 24-25.

Herzovich, M. (1971, julio 19). "El último reportaje”, Clarín, Buenos Aires, p. 15.

Lotersztain, I. (2014). La religión judeo-comunista en los tiempos de la URSS. La prensa del ICUF en Argentina entre 1946 y 1957. Tesis de Doctorado, inédita.

Piglia, R. (1975). “Germán Rozenmacher: el eco de su voz”. El Cronista Cultural, 16, 1-3.

Rozenmacher, G. (1964). "Diálogo a tres voces a la búsqueda de la realidad perdida”, Teatro $X X, \mathrm{~N}^{\circ}$ 2, Año I, p. 7. . (2013). Obras Completas. Buenos Aires: Biblioteca Nacional.

Senkman, L. (1983). La identidad judía en la literatura argentina. Buenos Aires: Pardés.

Slavsky, L. y Skura, S. (2002). “1901-2011. Cien años de teatro ídish en Buenos Aires” en Feierstein, Ricardo, Recreando la cultura judeoargentina. Buenos Aires: Milá.

Sosnowski, S. (1977). "Germán Rozenmacher: tradiciones, rupturas y desencuentros”, Revista de crítica literaria latinoamericana, $\mathrm{N}^{\circ}$ 6, Año III, Lima, 93-110.

. (1987). La orilla inminente: escritores judíos argentinos. Buenos Aires: Legasa. 
Svarch, A. (2005). El comunista sobre el tejado. Historia de la militancia comunista en la calle judía, tesis de grado inédita.

Trastoy, B.; Zayas de Lima, P. (2006). Lenguajes escénicos, Buenos Aires: Prometeo Libros.

Visacovsky, N. (2016). Argentinos, judíos y camaradas: tras la utopía socialista, Buenos Aires: Biblos.

Weltman, G. (1957). "IFT, teatro de la vida. En su XXV Aniversario", Revista Nai Teater, $\mathrm{N}^{\circ}$ 34, Año XXI, 1-2.

Zayas de Lima, P. (2001). Cultura judía, teatro nacional, Buenos Aires: Nueva Generación. 